\title{
BMJ Open Social and behavioural factors associated with depressive symptoms among university students in Cambodia: a cross-sectional study
}

\author{
Chanrith Ngin, ${ }^{1,2,3}$ Khuondyla Pal, ${ }^{1}$ Sovannary Tuot, ${ }^{1}$ Pheak Chhoun, ${ }^{1}$ Rosa Yi, ${ }^{3}$ \\ Siyan $\mathrm{Yi}^{1,4,5}$
}

To cite: Ngin C, Pal K, Tuot S, et al. Social and behavioural factors associated with depressive symptoms among university students in Cambodia: a crosssectional study. BMJ Open 2018;8:e019918. doi:10.1136/ bmjopen-2017-019918

- Prepublication history for this paper is available online. To view these files, please visit the journal online (http://dx.doi. org/10.1136/bmjopen-2017019918).

Received 5 0ctober 2017 Revised 3 September 2018 Accepted 4 September 2018

D Check for updates

(C) Author(s) (or their employer(s)) 2018. Re-use permitted under CC BY-NC. No commercial re-use. See rights and permissions. Published by BMJ.

${ }^{1}$ KHANA Center for Population Health Research, Phnom Penh, Cambodia

${ }^{2}$ Development Studies

Programme, University of Auckland, Auckland, New Zealand

${ }^{3}$ Faculty of Development Studies, Royal University of Phnom Penh, Phnom Penh, Cambodia

${ }^{4}$ Center for Global Health Research, Touro University California, Vallejo, CA, United States

${ }^{5}$ Saw Swee Hock School of Public Health, National University of Singapore and National University Health System, Singapore, Singapore

Correspondence to Dr Siyan Yi; siyan@doctor.com

\section{ABSTRACT}

Objective To explore social and behavioural factors associated with depressive symptoms among university students in Cambodia.

Design Cross-sectional study.

Settings Two public universities - one in the capital city of Phnom Penh and another in Battambang provincial town.

Participants This study included 1359 students randomly selected from all departments in the two universities using a multistage cluster sampling method for a selfadministered questionnaire survey in 2015.

Primary outcome measure Depressive symptoms measured by using the Center for Epidemiologic Studies Depression scale. All measures in the study were selfreported.

Results The proportion of students with depressive symptoms and severe depressive symptoms were $50.6 \%$ and $19.6 \%$, respectively. After adjustment in multivariate logistic regression analysis, depressive symptoms remained significantly associated with poor academic performance (adjusted OR (AOR) $=7.31,95 \% \mathrm{Cl} 2.24$ to 23.86), higher consumption of unhealthy food ( $A O R=1.72$, $95 \% \mathrm{Cl} 1.08$ to 2.76 ), a negative self-perception about body shape ( $A O R=0.54,95 \% \mathrm{Cl} 0.29$ to 0.99 ) and general health status ( $\mathrm{AOR}=2.99,95 \% \mathrm{Cl} 1.28$ to 7.00$)$, and limited physical activeness (AOR $=0.30,95 \% \mathrm{Cl} 0.16$ to 0.58). Depressive symptoms also remained significantly associated with adverse childhood experiences including physical violence ( $\mathrm{AOR}=1.39,95 \% \mathrm{Cl} 1.04$ to 1.86 ), psychological abuse (AOR=1.82, 95\% $\mathrm{Cl} 1.37$ to 2.42) and lack of general and medical care $(\mathrm{AOR}=0.51,95 \% \mathrm{Cl} 0.30$ to 0.86 ) by family during childhood.

Conclusions The key factors associated with depressive symptoms were family related and individual behaviours and attitudes. Thus, efforts should be invested in comprehensive screening and intervention programmes to diagnose those vulnerable students early, offer immediate treatment and cater appropriate support.

\section{INTRODUCTION}

Several studies have suggested that the aspects of mental health among university students are considerably poorer than that of their
Strengths and limitations of this study

- This research is among a very few studies in developing countries in which standardised tools are used and rigorous analyses are performed.

- It included a large sample of students randomly selected from all departments in two public universities - one in the capital city and the other in a provincial town-using a multistage cluster sampling method.

- Limitations of the study, however, included the representativeness of the study sample, the cross-sectional nature of the data that limits causation inferences, unknown validity of the scales used to measure important constructs in the Cambodian contexts and potential bias of self-reported measures.

peers in the general population. ${ }^{1-5}$ Depression is one of the most prevalent mental health problems among university students, and the prevalence is rising. ${ }^{6} 7$ There are varied prevalence estimates of depressive symptoms among university students, ranging from in the area of $10 \%^{8-11}$ to in the region of $20 \%^{12}$ and up to $40 \%$ and $80 \% \cdot{ }^{13-15}$ However, the mean prevalence of depression in university students stands at $30.6 \%{ }^{6}$ University students are in a critical period of life since they transition from adolescence to adulthood, which requires them to make many major decisions. During this period, they encounter tremendous pressures, chiefly from economic stress, academic demands, interpersonal relationships and struggles with making crucial decisions. ${ }^{16}$

Depression manifests in a wide range of symptoms, encompassing sleep and eating disturbances, lack of self-care, poor concentration, anxiety and disinterest in everyday activities. ${ }^{17}$ For university students, depression is correlated with poor academic 
achievements, ${ }^{18}$ drop-out, ${ }^{19}{ }^{20}$ relationship instability, ${ }^{21}$ suicidal ideation and attempts, ${ }^{1822} 23$ poor work performance, ${ }^{24}$ substance abuse, ${ }^{25}{ }^{26}$ acute infectious illnesses ${ }^{27}$ and poor physical and mental health in general. ${ }^{2829}$ Moreover, depression in this early period can build up negative consequences in adult life through its impacts on career prospects and social relationships. ${ }^{30} 31$

Thus, tackling depression among university students is vital since most lifetime mental disorders commence during the university age ${ }^{32}$ and their mental health has essential ramifications for campus health services in particular and mental health policy-making in general. ${ }^{33}{ }^{34}$ Put another way, from a public health standpoint, early detection and prevention of mental health problems among young adults in higher education is paramount. Comprehension of their salient psychological distress, namely depression, and its correlates would enable tailor-made and early screening and intervention programmes to reduce mental health problems in this population. This is integral for their educational performance and triumph in their prospective profession as well as for the national advancement since they are future leaders.

The prevalence of depression is induced by many factors, including study populations, sociodemographics, ${ }^{16}{ }^{35}$ study sites, ${ }^{1636}$ diagnostic tools and sampling methods ${ }^{3637}$ and sociocultural environments. ${ }^{16}$ Contextualisation of facets linked with depression thus is significant for mitigation measures.

In Cambodia, little is known about social and behavioural determinants of depressive symptoms among student populations. In 2012, a study on 1943 students at 11 junior high and high schools found that exposure to violence among community members, peers or family was a predictor for depressive symptoms in the students. ${ }^{38} 39$ A 2013 qualitative study on a sample of 28 students at a Cambodian university found that life events, problems of everyday life and availability of social support were the main stress factors affecting university students' life satisfaction. ${ }^{40}$ Moreover, exposure to daily hassles was a stress factor having a strong impact on students' psychological and somatic responses. Nonetheless, no research has been conducted to examine social and behavioural determinants of depression among Cambodian university students. This study therefore intends to identify factors associated with depressive symptoms among university students in Cambodia.

\section{METHODS}

\section{Study sites and population}

This cross-sectional study was conducted with students at the University of Battambang (UB) in Battambang province and the Royal University of Phnom Penh (RUPP) in the capital city of Cambodia in June and July 2015. Epi Info (Centers for Disease Control and Prevention, Atlanta, Georgia) was used to calculate the sample size from the university student population of approximately $168000 .{ }^{41}$ The anticipated percentage frequency was not known, so $50 \%$ was put for the calculation to prevent any underestimated prevalence. Based on a $95 \% \mathrm{CI}$ and a $+5 \%$ margin of error, the minimum sample size required for this study was 767 students. Adjusted for $10 \%$ of incomplete responses, missing data and rejection rate, the final minimum required sample size was 850 students.

\section{Patient and public involvement}

The development of the research questions and outcome measures was informed by university students' priorities, experience and preferences gathered through consultative meetings with representatives of students, faculty members and school administrators. The workshops aimed to collect inputs from the representatives for designing the study and developing the study protocol and materials. The representatives were also invited to participate in the study finding dissemination workshops in each participating university.

\section{Sampling and data collection procedure}

A multistage cluster sampling method was used to select the participants. First, the two universities were purposively selected, considering administration and logistic limitations. All departments of the selected universities were included in the study. In each department, a non-proportionate quota sampling method was used to select the sample from a name list provided by the department administrator to meet the required sample size. On the designated date of data collection, all selected students were approached by trained data collectors with support from a school administrator. Questionnaires and instructions were then distributed to them in a classroom for self-administration, which took approximately $30 \mathrm{~min}$ to complete.

\section{Questionnaire development and training}

We first developed a structured questionnaire in English and translated it into Khmer, the national language of Cambodia. Then, the Khmer questionnaire was back-translated into English by a local expert to check its accuracy. The Khmer questionnaire was pretested with a sample of 20 students at RUPP to ensure that the wording and contents were culturally suitable and clearly understandable. We also received comments on the questionnaire from experts working on health and education in Cambodia. The questionnaire was finalised based on their feedback and findings from the pretest. The questionnaire is available on request from the corresponding author.

A 2-day training on the study protocol and data collection methods was provided to the data enumerators and supervisors. The training focused on building familiarity with the study protocol and questionnaire, interview techniques, privacy assurance and confidentiality. It also addressed quality control strategies, such as rechecking and reviewing the questionnaires after administration, and resolving issues that might arise during the fieldwork. The data collection supervisors were instructed to 
perform regular reviews with the data enumerators to monitor progress and settle any issues occurring during the process.

\section{Variables and measurements}

Depressive symptoms

Depressive symptoms were assessed by using the Center for Epidemiologic Studies Depression scale (CES-D). ${ }^{42}$ This scale consists of 20 questions addressing six symptoms of depression, including depressed mood, guilt or worthlessness, helplessness or hopelessness, psychomotor retardation, loss of appetite and sleep disturbance experienced during the preceding week. Each question is scored on a scale of 0-3 according to the frequency of the symptoms, and the total CES-D score ranges from 0 to 60 . To calculate the total score, four items (I felt I was just as good as other people, I felt hopeful about the future, I was happy and I enjoyed life) were reverse coded. The criterion validity of the CES-D scale has been well established in Western ${ }^{42}$ and Asian ${ }^{43}$ populations. We defined depressive symptoms as present when a subject had a CES-D score of $\geq 16$. A cut-off value of $\geq 23$ was also used to define severe depressive state. ${ }^{44}$

\section{Sociodemographic characteristics, substance use and sexual behaviours}

We adapted standardised tools from the most recent Cambodia Demographic and Health Survey ${ }^{45}$ as well as from our previous student and young people health surveys in Cambodia ${ }^{38} 39$ 46-48 to measure socioeconomic characteristics, sexual behaviours with different partners and substance use (alcohol, tobacco and illicit drugs). Sociodemographic characteristics of the respondents included study site, gender, age, marital status, academic year, living situations, perceived family economic status and perceived academic performance.

\section{Health-related behaviours}

We used the Health Behavior Survey, ${ }^{49}$ which was designed as a broad survey of health-related behaviours and beliefs, components of the 'National College Health Risk Behavior Survey' (1997) ${ }^{50}$ and the Global Schoolbased Student Health Survey. ${ }^{51}$ Each health behaviour area was addressed by only a limited number of items. For example, frequency of consumption of fast food in an average week was assessed by a question, 'On average, how many times do you eat fast food per week?' with response options of 0 time, one to two times a week and three or more times a week. Similar questions and response options were used to assess consumption of several other kinds of healthy and unhealthy food, such as high-fat snack or fruits/vegetables. Self-ratings were also used for some questions, such as perceived body size (rated from very overweight to very underweight) and general health status (rated from very good to very poor).

\section{Adverse childhood experiences (ACEs)}

Five questions were adapted from the brief screening version of the Childhood Trauma Questionnaire to measure ACEs. ${ }^{52}$ The five yes/no questions asked about the experiences of physical abuse, emotional abuse, sexual abuse, physical neglect and emotional neglect during childhood.

Self-rated health

SF-12 Health Survey (SF-12) was used to measure selfrated health. ${ }^{53} 54$ The SF-12 is a multipurpose short-form generic measure of health status. It is a subset of the larger SF-36 and monitors health in general and in specific populations. The SF-12 measures eight health aspects, namely physical functioning, role limitations due to physical health problems, bodily pain, general health, vitality (energy/fatigue), social functioning, role limitations due to emotional problems and mental health (psychological distress and psychological well-being).

\section{Data analyses}

Double data entry was performed using EpiData version 3 (Odense, Denmark). $\chi^{2}$ test, or Fisher's exact test when a sample size was smaller than five in one cell, was used for categorical variables, and Student's t-test was used for continuous variables to compare sociodemographic characteristics, health risk behaviours (sexual behaviours, substance use and eating behaviours), self-rated health (SF-12) and ACEs among students with depressive symptoms, defined by a CES-D score of $\geq 16$, to those among students without depressive symptoms. The same comparisons were also made among students with and without severe depressive symptoms, defined by a CES-D score of $\geq 23$.

In multivariate models, we first included all variables significantly associated with depressive symptoms in the bivariate analyses at a level of $p$ value $<0.05$ simultaneously in the models. Variables with a p value $>0.05$ were then removed, and the models were refitted. The steps were repeated until all $p$ values of the remaining variables were $<0.05$ in the final models. Adjusted ORs (AORs) were obtained and presented with CI and $p$ values. SPSS V.22 was used for all statistical analyses.

\section{Ethical considerations}

Participation in this study was voluntary. In the process of obtaining a written informed consent, students were made clear that they could refuse or discontinue their participation at any time and for any reason. The confidentiality and privacy of the respondents were protected by administering the questionnaires in a private premise and by excluding personal identifiers from the data and field notes. After completing the survey, each participant received a small gift (costing approximately US\$ 2.0) for their time compensation.

\section{RESULTS}

\section{Sociodemographic characteristics}

The study sample included 493 students (36.3\%) from UB and 866 students (63.7\%) from RUPP. About half 
$(50.8 \%)$ of the respondents were male, with a mean age of 21.3 years $\mathrm{SD}=2.3$ ]. Less than $2.0 \% \quad(\mathrm{n}=26)$ of the students initially selected for the study declined the participation, mostly due to their time constrains. They were then replaced by the next gender-matched student in the student name list. The majority of the respondents (97.9\%) were unmarried, and $43.4 \%$ were living with their parents. Regarding their family economic status, $59.2 \%$ reported that their family was neither rich nor poor. The proportion of students with depressive symptoms and severe depressive symptoms were $50.6 \%$ and $19.6 \%$, respectively.

Table 1 shows that a significantly higher proportion of students with depressive symptoms were from UB $(\mathrm{p}=0.004)$ and from a poorer family $(\mathrm{p}=0.002)$ and reported poorer academic performance $(\mathrm{p}<0.001)$. Similarly, a significantly higher proportion of students with severe depressive symptoms were female $(\mathrm{p}=0.002)$ and from a poorer family

Table 1 Comparisons of sociodemographic characteristics of university students with and without depressive symptoms

\begin{tabular}{|c|c|c|c|c|c|c|}
\hline \multirow[b]{2}{*}{ Characteristics } & \multicolumn{3}{|c|}{ Depressive symptoms* } & \multicolumn{3}{|c|}{ Severe depressive symptoms $\dagger$} \\
\hline & No & Yes & $P$ values $¥$ & No & Yes & $P$ values $¥$ \\
\hline Study site & & & 0.004 & & & 0.08 \\
\hline Battambang & $218(44.2)$ & $275(55.8)$ & & 384 (77.9) & $109(22.1)$ & \\
\hline Phnom Penh & $454(52.4)$ & $412(47.6)$ & & 709 (81.9) & $157(18.1)$ & \\
\hline Gender & & & 0.20 & & & 0.002 \\
\hline Female & $319(47.7)$ & 350 (52.3) & & $515(77.0)$ & $154(23.0)$ & \\
\hline Male & $353(51.2)$ & $337(48.8)$ & & $578(83.8)$ & $112(16.2)$ & \\
\hline Age $($ mean $\pm S D)$ & $21.3 \pm 2.4$ & $21.4 \pm 2.3$ & 0.82 & $21.4 \pm 2.3$ & $21.1 \pm 2.4$ & 0.12 \\
\hline Marital status & & & 0.34 & & & 0.08 \\
\hline Unmarried & $655(49.2)$ & $675(50.8)$ & & $1066(80.2)$ & $264(19.8)$ & \\
\hline Married & $17(58.6)$ & $12(41.4)$ & & 27 (93.1) & $2(6.9)$ & \\
\hline Academic year & & & 0.59 & & & 0.66 \\
\hline 1 & $240(48.4)$ & $256(51.6)$ & & $394(79.4)$ & $102(20.6)$ & \\
\hline 2 & $145(51.6)$ & $136(48.4)$ & & $224(79.7)$ & $57(20.3)$ & \\
\hline 3 & $123(49.0)$ & $128(51.0)$ & & $201(80.1)$ & 50 (19.9) & \\
\hline 4 & $164(49.5)$ & $167(50.5)$ & & $274(82.8)$ & $57(17.2)$ & \\
\hline Currently living with & & & 0.35 & & & 0.70 \\
\hline Parents & 297 (49.9) & $298(50.1)$ & & $486(81.7)$ & 109 (18.3) & \\
\hline Relatives & $81(45.0)$ & 99 (55.0) & & 139 (77.2) & $41(22.8)$ & \\
\hline Sibling & $87(56.1)$ & $68(43.9)$ & & $124(80.0)$ & $31(20.0)$ & \\
\hline Friend & $162(50.2)$ & $161(49.8)$ & & 258 (79.9) & $65(20.1)$ & \\
\hline Spouse/partners & $10(47.6)$ & $11(52.4)$ & & 19 (90.5) & $2(9.5)$ & \\
\hline Alone & $26(41.9)$ & $36(58.1)$ & & $50(80.6)$ & $12(19.4)$ & \\
\hline Other & $9(39.1)$ & $14(60.9)$ & & 17 (73.9) & $6(26.1)$ & \\
\hline Perceived family economic status & & & 0.002 & & & 0.04 \\
\hline Well-off/quite well-off & $248(55.7)$ & $197(44.3)$ & & $374(84.0)$ & $71(16.0)$ & \\
\hline Neither poor nor well-off & $398(47.0)$ & $448(53.0)$ & & $669(71.1)$ & $177(20.9)$ & \\
\hline Poor & $26(38.2)$ & $42(61.8)$ & & $50(73.5)$ & $18(26.5)$ & \\
\hline Perceived academic performance & & & $<0.001$ & & & $<0.001$ \\
\hline Very good & $44(77.2)$ & $13(22.8)$ & & $52(91.2)$ & $5(5.8)$ & \\
\hline Good & $180(59.0)$ & $123(40.6)$ & & $263(86.8)$ & $40(13.2)$ & \\
\hline Fairly good & $301(50.5)$ & $295(49.5)$ & & $484(81.2)$ & $112(18.8)$ & \\
\hline Fair & $138(37.7)$ & $228(62.3)$ & & $275(75.1)$ & $91(24.9)$ & \\
\hline Poor & 9 (24.3) & $28(75.7)$ & & $19(51.4)$ & $18(48.6)$ & \\
\hline
\end{tabular}

Values are numbers of subjects (\%) for categorical variables and means \pm SD for continuous variables.

${ }^{*}$ Defined by a Center for Epidemiology Studies Depression Scale (CES-D) score of $\geq 16$.

†Defined by a CES-D score of $\geq 23$.

$\ddagger \chi^{2}$ test was used for categorical variables; independent Student's t-test was used for continuous variables. 
$(\mathrm{p}=0.04)$ and reported poorer academic performance $(\mathrm{p}<0.001)$.

\section{Health risk behaviours}

As shown in table 2, a significantly higher proportion of students with depressive symptoms reported consuming unhealthy food frequently, such as high-fat snack ( $p=0.001$ for depressive symptoms; $p<0.001$ for severe depressive symptoms), margarine, butter or meat fat $(p=0.02$ for depressive symptoms; $p<0.001$ for severe depressive symptoms). A significantly lower proportion of students with depressive symptoms reported consuming of healthy food frequently, such as fruits and vegetables ( $\mathrm{p}=0.009$ for depressive symptoms; $\mathrm{p}=0.007$ for severe depressive symptoms), or lean protein $(\mathrm{p}<0.001$ for depressive symptoms; $p=0.03$ for severe depressive symptoms). A significantly higher proportion of students with depressive symptoms reported not having dessert over the past week ( $\mathrm{p}=0.003$ for depressive symptoms; $\mathrm{p}=0.008$ for severe depressive symptoms). Moreover, a significantly higher proportion of students with depressive symptoms perceived that their body size was very overweight or very underweight $(\mathrm{p}<0.001$ for both depressive symptoms and severe depressive symptoms).

\section{Self-rated health (SF-12)}

Table 3 shows that significantly higher proportion of students with depressive symptoms perceived that their general health status was poor $(p<0.001$ for both depressive symptoms and severe depressive symptoms). A significantly higher proportion of students with depressive symptoms reported higher levels of limitation in several daily activities, such as limitation in moderate activities ( $\mathrm{p}<0.001$ for depressive symptoms; $\mathrm{p}=0.02$ for severe depressive symptoms), climbing several flights of stairs ( $<<0.001$ for depressive symptoms) or other kinds of activities in the past 4 weeks as a result of their physical or emotional health problems $(\mathrm{p}<0.001$ for both depressive symptoms and severe depressive symptoms). Furthermore, they reported higher levels of problems in several other physical and emotional health aspects in the past 4 weeks, such as a feeling that they had accomplished less than they would like $(p<0.001$ for both depressive symptoms and severe depressive symptoms), pain interferes with their normal work ( $<<0.001$ for both depressive symptoms and severe depressive symptoms), having less energy $(\mathrm{p}<0.001$ for both depressive symptoms and severe depressive symptoms), downhearted and blue $(\mathrm{p}<0.001$ for both depressive symptoms and severe depressive symptoms) and that their physical health interferes with their social acts $(p<0.001$ for both depressive symptoms and severe depressive symptoms).

\section{Adverse childhood experiences}

As shown in table 4, a significantly higher proportion of students with depressive symptoms reported having been hit, slapped or kicked by a parent or guardian $(p<0.001$ for both depressive symptoms and severe depressive symptoms); that people in their family had said hurtful or insulting things to them ( $<<0.001$ for both depressive symptoms and severe depressive symptoms); and that someone had tried to touch them or make them touch him or her in a sexual way $(\mathrm{p}=0.001$ for depressive symptoms; $\mathrm{p}<0.001$ for severe depressive symptoms). In contrast, significantly lower proportion of students with depressive symptoms reported that there had been someone to take care of them and take them to medical care when they got sick ( $\mathrm{p}=0.04$ for depressive symptoms; $\mathrm{p}=0.03$ for severe depressive symptoms) and someone who helped them feel that they were loved and important ( $\mathrm{p}=0.03$ for depressive symptoms; $\mathrm{p}<0.001$ for severe depressive symptoms).

\section{Risk factors of depressive symptoms}

Results of multivariate logistic analyses are shown in table 5. After controlling for potential confounding factors, the odds of depressive symptoms increased significantly with self-reported poor academic performance (depressive symptoms: AOR $=7.31,95 \%$ CI 2.24 to 23.86; severe depressive symptoms: $\mathrm{AOR}=7.38,95 \%$ CI 1.75 to 10.94 ) and high consumption of unhealthy food, including high-fat snack, margarine, butter or meat fat (depressive symptoms: AOR $=1.72,95 \%$ CI 1.08 to 2.76; severe depressive symptoms: $\mathrm{AOR}=2.13,95 \% \mathrm{CI}$ 1.15 to 3.95$)$. The odds decreased significantly with the perception that their body size was slightly underweight compared with the perception that their body size was very overweight (depressive symptoms: $\mathrm{AOR}=0.54,95 \%$ CI 0.29 to 0.99 ; severe depressive symptoms: $\mathrm{AOR}=0.37$, $95 \%$ CI 0.18 to 0.77 ).

Regarding self-rated health, the odds of depressive symptoms increased significantly with the perception that their general health status was poor (depressive symptoms: $\mathrm{AOR}=2.99,95 \%$ CI 1.28 to 7.00 ; severe depressive symptoms: AOR $=5.43$, 95\% CI 2.19 to 13.46 ) and the report of higher level of limitation in moderate activities (depressive symptoms: AOR $=0.30,95 \%$ CI 0.16 to 0.58 ), higher level of pain interference with their normal work (depressive symptoms: AOR $=10.43,95 \%$ CI 1.05 to 10.94 ; severe depressive symptoms: AOR $=10.02,95 \%$ CI 1.99 to 9.28) and higher level of feeling downhearted and blue (depressive symptoms: $\mathrm{AOR}=6.69,95 \%$ CI 1.87 to 23.90; severe depressive symptoms: AOR=8.72, 95\% CI 1.69 to 14.86).

For ACEs, the odds of depressive symptoms increased significantly with the report of having been hit, slapped or kicked by a parent or guardian (depressive symptoms: $\mathrm{AOR}=1.39,95 \%$ CI 1.04 to 1.86 ) and that people in their family had said hurtful or insulting things to them (depressive symptoms: $\mathrm{AOR}=1.82,95 \%$ CI 1.37 to 2.42; severe depressive symptoms: $\mathrm{AOR}=2.18,95 \%$ CI 1.46 to 3.24$)$ during their childhood. In contrast, the odds of depressive symptoms decreased significantly with the report that there had been someone to take care of them and take them to medical care when they got sick (depressive symptoms: $\mathrm{AOR}=0.51,95 \%$ CI 0.30 to 0.86 ; 
Table 2 Comparisons of health risk behaviours among university students with and without depressive symptoms

\begin{tabular}{|c|c|c|c|c|c|c|}
\hline \multirow{2}{*}{$\begin{array}{l}\text { Health and health risk } \\
\text { behaviours }\end{array}$} & \multicolumn{3}{|c|}{ Depressive symptoms* } & \multicolumn{3}{|c|}{ Severe depressive symptoms $†$} \\
\hline & No & Yes & $P$ values $\neq$ & No & Yes & $P$ values $\neq$ \\
\hline Current tobacco smokers & 5 (33.3) & $10(66.7)$ & & $12(80.0)$ & $3(20.0)$ & 0.97 \\
\hline \multicolumn{2}{|l|}{ Self-perception regarding alcohol use } & & 0.25 & & & 0.004 \\
\hline Non drinker & $425(50.7)$ & $413(49.3)$ & & $681(81.3)$ & $157(18.7)$ & \\
\hline Occasional drinker & $247(47.4)$ & $271(52.6)$ & & $412(78.7)$ & $106(21.3)$ & \\
\hline Regular drinker & $0(0.0)$ & $3(100)$ & & $0(0.0)$ & $3(100)$ & \\
\hline Current illicit drug users & $0(0.0)$ & $4(100)$ & 0.05 & $1(25.0)$ & $3(75.0)$ & 0.03 \\
\hline Condom use at last sex & $39(47.0)$ & $44(53.0)$ & 0.95 & $73(88.0)$ & $10(12.0)$ & 0.08 \\
\hline Diagnosed with an STI & $4(40.0)$ & $6(60.0)$ & 0.75 & $110(84.0)$ & $21(16.0)$ & 0.67 \\
\hline Thought of ending life & $40(24.8)$ & $121(75.2)$ & $<0.001$ & $84(52.2)$ & $77(47.8)$ & $<0.001$ \\
\hline Attempted to end life & $5(20.0)$ & $20(80.0)$ & 0.63 & $11(44.0)$ & $14(56.0)$ & 0.47 \\
\hline \multicolumn{2}{|c|}{ Frequency of eating fast food per week } & & 0.49 & & & 0.24 \\
\hline 0 time & $410(49.3)$ & $421(50.7)$ & & $679(81.7)$ & $152(18.3)$ & \\
\hline $1-2$ times & $231(50.7)$ & $225(49.3)$ & & $360(78.9)$ & $96(21.1)$ & \\
\hline 3 times or more & $31(43.1)$ & $41(56.9)$ & & $54(75.0)$ & $18(25.0)$ & \\
\hline \multicolumn{2}{|c|}{ Frequency of daily soft drink consumption } & & 0.31 & & & 0.01 \\
\hline 0 time & $105(46.5)$ & $121(53.5)$ & & $178(78.8)$ & $48(21.2)$ & \\
\hline $1-2$ times & $399(51.2)$ & $380(48.8)$ & & $647(83.1)$ & $132(16.9)$ & \\
\hline 3 times or more & $168(47.5)$ & $186(52.5)$ & & $268(75.7)$ & $86(24.3)$ & \\
\hline \multicolumn{2}{|c|}{ Frequency of weekly high-fat snack consumption } & & 0.001 & & & $<0.001$ \\
\hline 0 time & $162(52.8)$ & $145(47.2)$ & & $260(84.7)$ & 47 (15.3) & \\
\hline $1-2$ times & $443(51.0)$ & $426(49.0)$ & & $711(81.8)$ & $158(18.2)$ & \\
\hline 3 times or more & $67(36.6)$ & $116(63.4)$ & & $122(66.7)$ & $61(33.3)$ & \\
\hline \multicolumn{2}{|c|}{ Frequency of weekly dessert consumption } & & 0.003 & & & 0.008 \\
\hline 0 time & $106(40.6)$ & $155(59.4)$ & & $192(73.6)$ & $69(26.4)$ & \\
\hline $1-2$ times & $434(52.7)$ & $389(47.3)$ & & $676(82.1)$ & $147(17.9)$ & \\
\hline 3 times or more & $132(48.0)$ & $143(52.0)$ & & $225(81.8)$ & $50(18.2)$ & \\
\hline \multicolumn{2}{|c|}{ Frequency of weekly fruit/vegetable consumption } & & 0.009 & & & 0.007 \\
\hline 0 time & $50(37.3)$ & $84(62.7)$ & & $94(70.1)$ & 40 (29.9) & \\
\hline $1-2$ times & $390(51.7)$ & $365(48.3)$ & & $617(81.7)$ & $138(18.3)$ & \\
\hline 3 times or more & $232(49.4)$ & $238(50.6)$ & & $382(81.3)$ & $88(12.7)$ & \\
\hline $\begin{array}{l}\text { Frequency of weekly lean protein } \\
\text { consumption }\end{array}$ & & & $<0.001$ & & & 0.03 \\
\hline 0 time & 57 (34.8) & $107(65.2)$ & & $119(72.6)$ & $45(27.4)$ & \\
\hline $1-2$ times & $453(51.8)$ & $421(48.2)$ & & $714(81.7)$ & $160(18.3)$ & \\
\hline 3 times or more & $162(50.5)$ & $159(49.5)$ & & $260(81.0)$ & $61(19.0)$ & \\
\hline $\begin{array}{l}\text { Amount of margarine/butter/ } \\
\text { meat fat consumption }\end{array}$ & & & 0.02 & & & $<0.001$ \\
\hline None/very little & $296(52.4)$ & $269(47.6)$ & & $471(83.4)$ & $94(16.6)$ & \\
\hline Some & $339(48.7)$ & $357(51.3)$ & & $558(80.2)$ & $138(19.8)$ & \\
\hline A lot & $37(37.8)$ & $61(62.2)$ & & $64(65.3)$ & $34(34.7)$ & \\
\hline Self-perception about body size & & & $<0.001$ & & & $<0.001$ \\
\hline About right & $275(55.4)$ & $221(44.6)$ & & $428(86.3)$ & $68(13.7)$ & \\
\hline Very overweight & $27(34.2)$ & $52(65.8)$ & & $55(69.6)$ & $24(30.4)$ & \\
\hline
\end{tabular}


Table 2 Continued

\begin{tabular}{|c|c|c|c|c|c|c|}
\hline \multirow{2}{*}{$\begin{array}{l}\text { Health and health risk } \\
\text { behaviours }\end{array}$} & \multicolumn{3}{|c|}{ Depressive symptoms* } & \multicolumn{3}{|c|}{ Severe depressive symptoms $†$} \\
\hline & No & Yes & $P$ values $¥$ & No & Yes & $P$ values $\neq$ \\
\hline Slightly overweight & $161(48.9)$ & $168(51.1)$ & & $247(75.1)$ & $82(24.9)$ & \\
\hline Slightly underweight & $191(49.6)$ & $194(50.4)$ & & 319 (82.9) & $66(17.1)$ & \\
\hline Very underweight & $18(25.7)$ & $52(74.3)$ & & 44 (62.9) & $26(37.1)$ & \\
\hline
\end{tabular}

Values are numbers of subjects (\%).

*Defined by a Center for Epidemiology Studies Depression Scale (CES-D) score of $\geq 16$.

$\dagger$ Defined by a CES-D score of $\geq 23$.

$\ddagger \chi^{2}$ test was used or Fisher's exact test was used as appropriate.

$\mathrm{STI}$, sexually transmitted infection.

severe depressive symptoms: $\mathrm{AOR}=0.26,95 \%$ CI 0.13 to $0.52)$.

\section{DISCUSSION}

This study explored the prevalence of depressive symptoms and unearthed a number of social and behavioural factors correlated with the symptoms among university students in Cambodia. The proportion of students with depressive symptoms and severe depressive symptoms was $50.6 \%$ and $19.6 \%$, respectively. The salient factors comprised cultural and socioeconomic dimensions (socioeconomic background and lack of general and medical care by family during their childhood), individual behaviours and attitudes (poor academic accomplishment, consumption of unhealthy food, negative perception about their body and their general health status and limited physical activeness) and nurture-related facets (physical violence and psychological abuse by family during their childhood).

The bivariate outcomes display that students from the provincial university (UB) and a poorer family were more susceptible to depressive symptoms. Although not manifesting in the multivariate model, these factors are corroborated by the existing scholarship. Various studies revealed that university students from rural areas and low socioeconomic backgrounds were predisposed to higher depression. ${ }^{1} 16285556$ This could be explained by an economic situation where students with a rural background tended to stipulate a poorer family status. Plus, financial vulnerability could further exacerbate depression in students from low-income families. A meta-analysis of 60 studies unveiled that people in the lowest socioeconomic quintile had 1.81 the probability of depression compared with those in the highest socioeconomic quintile. ${ }^{57} \mathrm{~A}$ global study on 17348 university students from 23 high-income, middle-income and low-income countries also uncovered that higher depressive symptoms were recorded among students in low-income countries and economies with greater income inequality. ${ }^{16}$ The Cambodian economy has been growing rapidly in terms of income per capita; yet, income gaps between the rich and the poor and between rural and urban areas remain large ${ }^{58}$ The gaps in income and material growth, which typify economic conditions, may induce people's mental health problems. In another word, poor economic status may bring about low self-esteem and self-confidence, which would lead to depression.

Our multivariate results depict that students with depressive symptoms, regardless of severity, tended to report poor academic performance and higher consumption of unhealthy food. These findings conform to a systematic review of 24 studies $^{6}$ and studies in Asia, such as China, ${ }^{7}$ which pinpoint low scholastic merit and suicidal ideation as consistent correlates of depression in university students probably as a culmination of poor concentration and solitude. On the consumption of unhealthy food, the transition from adolescence to adulthood, and thus the changes in lifestyle such as living arrangements and independence, might have rendered university students to indulge in unhealthy food, as pinpointed by a meta-analysis of 39 studies in China. ${ }^{7}$ As aforementioned, more than half of our sample were not living with their parents; therefore, it might have been hard for them to maintain healthy daily food. Conversely, depression might have made students care-free about themselves and consequently eat unhealthily. ${ }^{17}$ This implies that nutrition education for both physical and mental health, stressing healthy food for the body and mind, is imperative for university students.

Students with depressive symptoms, regardless of magnitude, also tended to have a negative perception about their body and their general health status. These findings confirms the general perception among depressed people who are not gratified with their body and health, ${ }^{17}$ although these relationships require a cautious interpretation given that CES-D also measures some aspects of negative self-perception. Furthermore, depressed students were more likely to have limited physical activeness, more pain interference with their normal work and more dismay or sorrow. These findings are consistent with findings from previous studies in different populations and settings. ${ }^{59}{ }^{60}$ However, the interpretation of these complex relationships must be made with caution given that the nature of the data does not allow causal relationship to be established. 
Table 3 Comparisons of self-rated health (SF-12) among university students with and without depressive symptoms

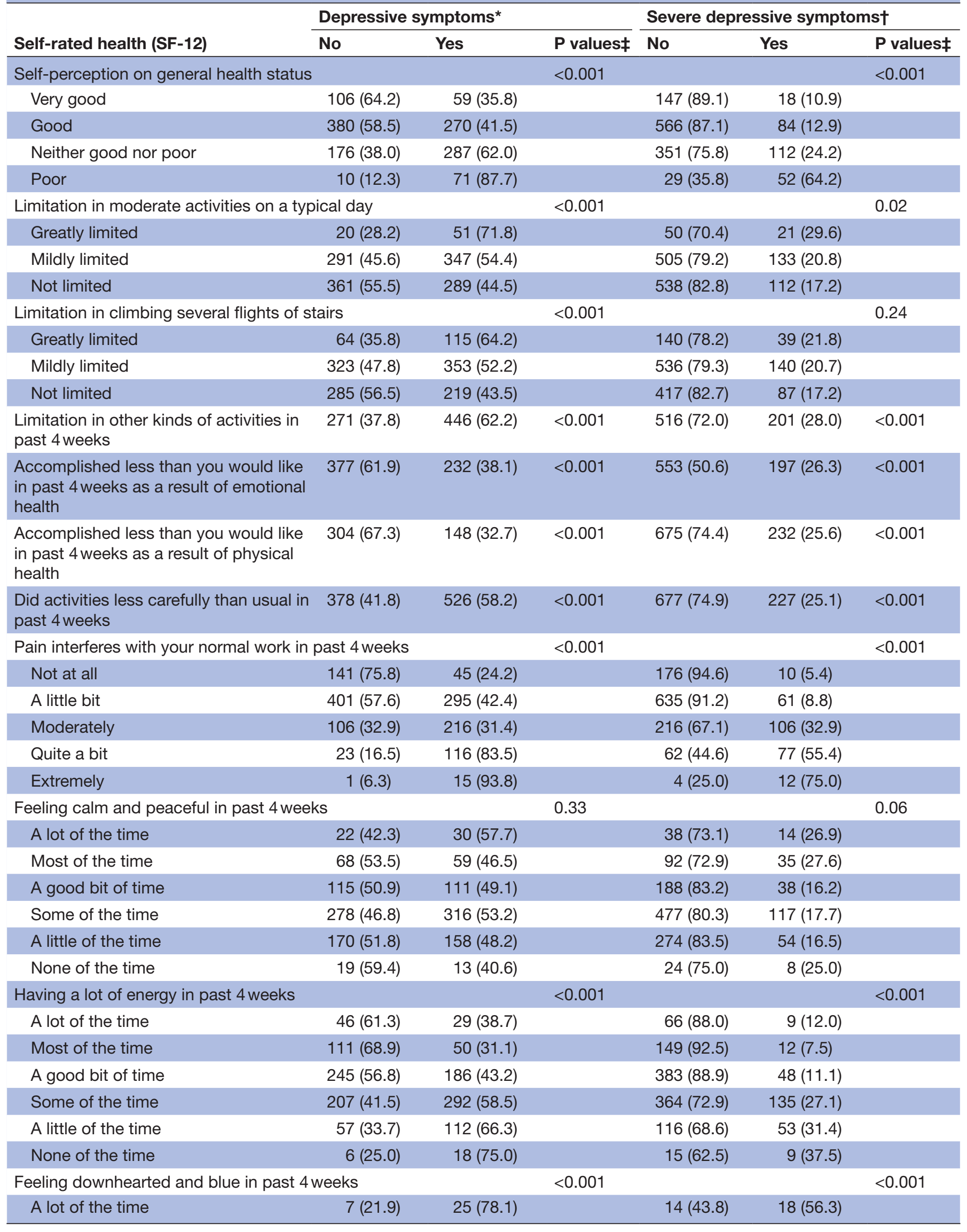

Continued 
Table 3 Continued

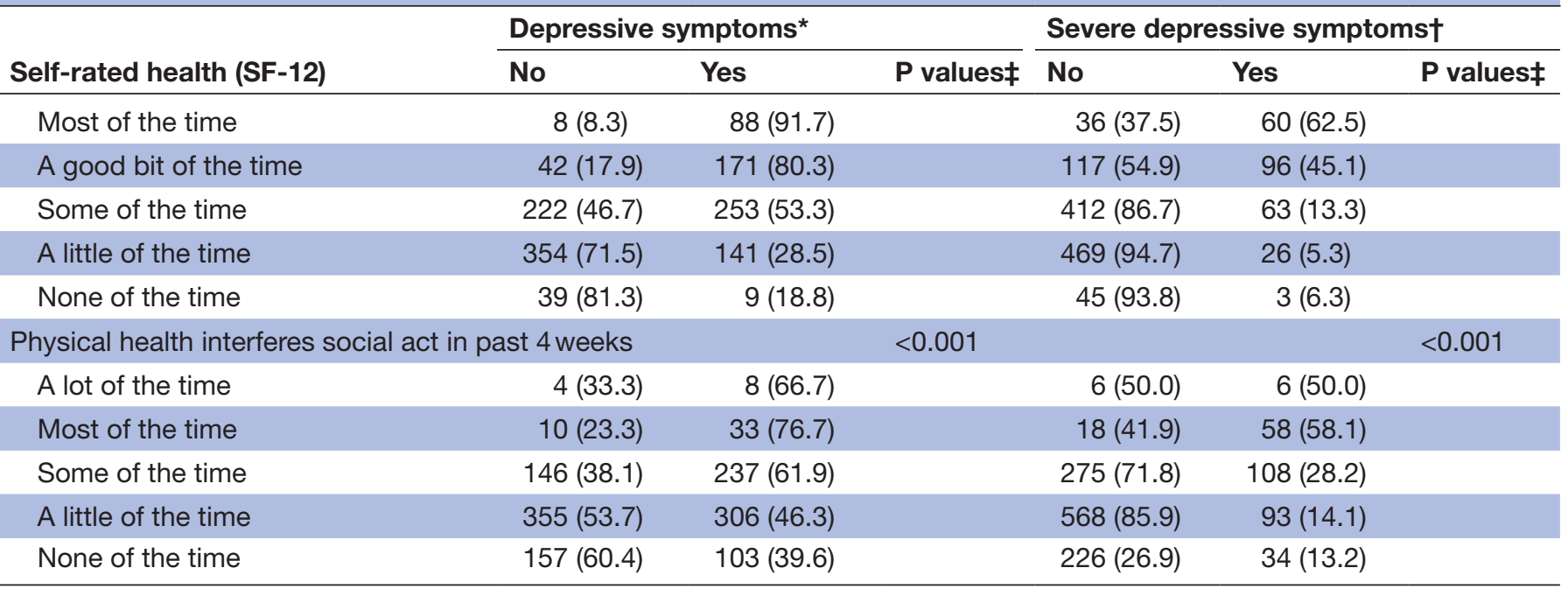

Values are numbers of subjects (\%) for categorical variables.

*Defined by a Center for Epidemiology Studies Depression Scale (CES-D) score of $\geq 16$.

†Defined by a CES-D score of $\geq 23$.

$\ddagger \chi^{2}$ test was used for categorical variables or Fisher's exact test was used as appropriate.

Finally, students with depressive symptoms, disregard of severity, were more likely to encounter physical violence by their parent or guardian, psychological abuse by their family members and lack of general and medical care by their family when they were growing up. As for the physical violence and psychological abuse, this finding tends to acquiesce with a study in Cambodia that postulates that exposure to violence within family is associated with depression in high school students. ${ }^{38}$ On the lack of general and medical care by family, a Chinese study on 5245 students at six universities found that students who had a poor parental relationship were more vulnerable to depression. ${ }^{11}$ Also, a global study on 17348 university students from 23 high-income, middle-income and low-income countries iterated that university students with less individualistic cultures, particularly in Asia, reported higher extents of depressive symptoms. ${ }^{16}$ Students of these cultures longed for more familial and societal ties and assistance, and thus felt depressed once this social capital was unavailable. ${ }^{16}$ This highlights a significant role of family bonds and scaffolding in association with depression among university students. The lack of social support from the family presumably would only be a factor for students living independently. However, for those living with relatives, friends or spouse, they would still have such support.

A study on a sample of 2671 respondents in nine provinces and a capital city in 2012 revealed that Cambodia greatly needs more and better counselling and mental health services. ${ }^{61}$ The study also pointed out the shortage of skilled professionals in the field of mental health, particularly those

Table 4 Comparisons of adverse childhood experiences among university students with and without depressive symptoms

\begin{tabular}{|c|c|c|c|c|c|c|}
\hline \multirow[b]{2}{*}{ Adverse childhood experiences } & \multicolumn{3}{|c|}{ Depressive symptoms* } & \multicolumn{3}{|c|}{ Severe depressive symptoms } \\
\hline & No & Yes & P values $¥$ & No & Yes & $P$ values $\ddagger$ \\
\hline $\begin{array}{l}\text { Had been hit, slapped and kicked by a } \\
\text { parent/guardian. }\end{array}$ & $200(38.2)$ & $323(61.8)$ & $<0.001$ & $384(73.4)$ & $139(26.6)$ & $<0.001$ \\
\hline $\begin{array}{l}\text { People in my family had said hurtful or } \\
\text { insulting things to me. }\end{array}$ & 297 (39.0) & $464(61.0)$ & $<0.001$ & $558(73.3)$ & $203(26.7)$ & $<0.001$ \\
\hline $\begin{array}{l}\text { Someone had tried to touch me or } \\
\text { make me touch them in a sexual way. }\end{array}$ & $87(39.2)$ & $135(60.8)$ & 0.001 & 159 (71.6) & $63(28.4)$ & $<0.001$ \\
\hline $\begin{array}{l}\text { There had been someone to take care } \\
\text { me and take me to medical care when I } \\
\text { got sick. }\end{array}$ & $636(50.2)$ & $632(49.8)$ & 0.04 & $1028(81.1)$ & $240(18.9)$ & 0.03 \\
\hline $\begin{array}{l}\text { There had been someone who helped } \\
\text { me feel that I was loved and important. }\end{array}$ & $647(50.1)$ & $644(49.9)$ & 0.03 & $1050(81.3)$ & $266(19.6)$ & $<0.001$ \\
\hline
\end{tabular}

Values are numbers of subjects (\%).

${ }^{*}$ Defined by a Center for Epidemiology Studies Depression Scale (CES-D) score of $\geq 16$.

$\dagger$ Defined by a CES-D score of $\geq 23$.

$\ddagger \chi^{2}$ test was used. 
Table 5 Factors associated with depressive symptoms and severe depressive symptoms

\begin{tabular}{|c|c|c|c|c|}
\hline \multirow[b]{2}{*}{ Variables in the final model* } & \multicolumn{2}{|c|}{ Depressive symptoms $\dagger$} & \multicolumn{2}{|c|}{ Severe depressive symptoms } \\
\hline & AOR $(95 \% \mathrm{Cl})$ & $P$ values & AOR $(95 \% \mathrm{Cl})$ & $P$ values \\
\hline \multicolumn{5}{|c|}{ Perceived academic performance } \\
\hline Very good & Reference & & Reference & \\
\hline Good & $2.28(1.01$ to 5.15$)$ & 0.04 & $1.22(0.35$ to 4.19$)$ & 0.76 \\
\hline Fairly good & 3.51 (1.58 to 7.78$)$ & 0.002 & 2.15 (0.65 to 7.11$)$ & 0.21 \\
\hline Fair & 5.30 (2.35 to 11.93$)$ & $<0.001$ & $2.52(0.75-8-43)$ & 0.13 \\
\hline Poor & $7.31(2.24$ to 23.86$)$ & 0.001 & 7.38 (1.75 to 10.94$)$ & 0.006 \\
\hline \multicolumn{5}{|c|}{ Frequency of weekly high-fat snack consumption } \\
\hline 0 time & Reference & & Reference & \\
\hline $1-2$ times & $0.99(0.72$ to 1.37$)$ & 0.95 & 1.25 (0.78 to 1.99$)$ & 0.36 \\
\hline 3 times or more & $1.72(1.08$ to 2.76$)$ & 0.02 & 2.13 (1.15 to 3.95$)$ & 0.02 \\
\hline \multicolumn{5}{|c|}{ Frequency of weekly lean protein consumption } \\
\hline 0 time & Reference & & Reference & \\
\hline $1-2$ times & 0.52 (0.34 to 0.79$)$ & 0.002 & $0.69(0.41$ to 1.18$)$ & 0.17 \\
\hline 3 times or more & $0.62(0.38$ to 0.96$)$ & 0.04 & $0.80(0.44$ to 1.47$)$ & 0.48 \\
\hline \multicolumn{5}{|c|}{ Amount of margarine/butter/meat fat consumption } \\
\hline None/very little & & & Reference & \\
\hline Some & & & 0.98 (0.66 to 1.46$)$ & 0.91 \\
\hline A lot & & & 1.92 (1.02 to 3.64$)$ & 0.04 \\
\hline \multicolumn{5}{|l|}{ Self-perception about body shape } \\
\hline Very overweight & Reference & & & \\
\hline Slightly overweight & 0.56 (0.31 to 1.07$)$ & 0.08 & 0.65 (0.32 to 1.14$)$ & 0.25 \\
\hline About right & $0.58(0.32$ to 1.05 & 0.07 & 0.45 (0.22 to 0.93$)$ & 0.03 \\
\hline Slightly underweight & 0.54 (0.29 to 0.99$)$ & 0.04 & 0.37 (0.18 to 0.77$)$ & 0.008 \\
\hline Very underweight & $0.92(0.38$ to 2.25$)$ & 0.86 & $0.38(0.14$ to 0.99$)$ & 0.04 \\
\hline \multicolumn{5}{|c|}{ Self-perception on general health status } \\
\hline \multicolumn{5}{|c|}{ Very good } \\
\hline Good & 1.05 (0.68 to 1.64$)$ & 0.82 & 1.19 (0.60 to 2.38$)$ & 0.62 \\
\hline Fair & 1.58 (0.99 to 2.51$)$ & 0.05 & 1.47 (0.73 to 2.96$)$ & 0.28 \\
\hline Poor & 2.99 (1.28 to 7.00$)$ & 0.01 & 5.43 (2.19 to 13.46$)$ & $<0.001$ \\
\hline \multicolumn{5}{|c|}{ Limitation in moderate activities on a typical day } \\
\hline Greatly limited & Reference & & Reference & \\
\hline Mildly limited & $0.39(0.20$ to 0.74$)$ & 0.004 & 0.64 (0.29 to 1.34$)$ & 0.23 \\
\hline Not limited & $0.30(0.16$ to 0.58$)$ & $<0.001$ & $0.63(0.30$ to 1.36$)$ & 0.24 \\
\hline
\end{tabular}

Pain interferes with your normal work in past 4 weeks

\begin{tabular}{lcccr} 
Not at all & Reference & \multicolumn{1}{c}{ Reference } & \multicolumn{1}{c}{0.99} \\
A little bit & $1.68(1.08$ to 2.61$)$ & 0.02 & 1.01 (0.46 to 2.22$)$ & 0.001 \\
Moderately & $3.10(1.89$ to 5.10$)$ & $<0.001$ & $3.69(1.68$ to 7.11$)$ & $<0.001$ \\
Quite a bit & $4.14(2.13$ to 8.05$)$ & $<0.001$ & $4.68(2.01$ to 10.92$)$ & 0.005 \\
Extremely & $10.43(1.05$ to 10.94$)$ & 0.04 & $10.02(1.99$ to 9.28$)$ &
\end{tabular}

Feeling downhearted and blue in past 4 weeks

$\begin{array}{lllll}\text { None of the time } & \text { Reference } & & \text { Reference } & \\ \text { A little of the time } & 0.52(0.63 \text { to } 3.66) & 0.35 & 1.02(0.24 \text { to } 4.29) & 0.98 \\ \text { Some of the time } & 3.42(1.42 \text { to } 8.23) & 0.006 & 1.83(0.45 \text { to } 7.45) & 0.40 \\ \text { A good bit of the time } & 7.70(3.02 \text { to } 19.66) & <0.001 & 6.01(1.45 \text { to } 4.85) & 0.01\end{array}$


Table 5 Continued

\begin{tabular}{|c|c|c|c|c|}
\hline \multirow[b]{2}{*}{ Variables in the final model ${ }^{*}$} & \multicolumn{2}{|c|}{ Depressive symptoms† } & \multicolumn{2}{|c|}{ Severe depressive symptomsł } \\
\hline & AOR $(95 \% \mathrm{Cl})$ & P values & AOR $(95 \% \mathrm{Cl})$ & P values \\
\hline Most of the time & 20.71 (6.47 to 66.37$)$ & $<0.001$ & $9.04(2.31$ to 13.71$)$ & 0.002 \\
\hline \multicolumn{5}{|c|}{ Had been hit, slapped and kicked by a parent/guardian } \\
\hline No & Reference & & Reference & \\
\hline \multicolumn{5}{|c|}{ People in my family had said hurtful or insulting things to me } \\
\hline No & Reference & & Reference & \\
\hline Yes & 1.82 (1.37 to 2.42$)$ & $<0.001$ & 2.18 (1.46 to 3.24$)$ & $<0.001$ \\
\hline \multicolumn{5}{|c|}{ There had been someone to take care of me and take me to medical care when I got sick } \\
\hline No & Reference & & Reference & \\
\hline
\end{tabular}

*Variables in the table were the ones that remained statistically significant in the final multivariate logistic regression model after several steps of model fitting.

†Defined by a Center for Epidemiology Studies Depression Scale (CES-D) score of $\geq 16$.

$\neq$ Defined by a CES-D score of $\geq 23$.

AOR, adjusted OR.

with high clinical and counselling skills to treat mental disorders. In 2012, Cambodia had only 49 trained psychiatrists and 45 psychiatric nurses working in mental health facilities and private practices for a population of approximately 15 million. ${ }^{61}{ }^{62}$ This number equates to approximately 0.2 psychiatrists per 100000 population, which is similar to the average in Southeast Asia. ${ }^{62}$ Many health staff lack training, supervision and experience in these areas. Only about 300 doctors completed basic mental healthcare training. ${ }^{63}$ At university level, the 2012 study called for more awareness raising for self-care and burnout prevention and mental health counselling services for staff and students. ${ }^{61}$ Given the paucity of mental health services in general, let alone at universities, our findings fuel the needs for more and better mental healthcare in Cambodia. Further to medical care, universities should provide measures, such as student loans and healthy canteens, to mitigate some key predictors of depression among students, such as financial hardship and poor diets.

This study contains certain limitations. First, it examined students at only two public universities, one in the capital city and the other in a province. Hence, its findings cannot be generalised at a national level. Second, the cross-sectional design did not enable an establishment of the causal linkages between depressive symptoms and the related factors. Given the temporal order and the cross-sectional nature of the data, causal relationships between the variables could not be derived. Potential bidirectionality of the associations could occur either way. For instance, physical inactivity could cause depression. Nonetheless, the reverse could also be true-that depression could lead to inactivity, and of course both could be true simultaneously, where depressive symptoms worsen with physical inactivity, making physical activity less likely.
Third, this study employed self-reported data, which might have been subject to over-reporting and under-reporting caused by the negative cognitive biases associated with depression as well as possible recall bias. Future studies should attempt to use more objective data (eg, linking participants' responses to university records of academic performance) to increase validity of the information. Nonetheless, the quality of the data was ensured by thorough training of the enumerators and field supervisors on the study protocols and data collection method. Finally, the main outcome measure (CES-D) and some other measures, such as ACEs and SF-12, were modified from other research and have not been validated in the Cambodian settings. Therefore, the interpretation of the findings must be made with caution. Notwithstanding these malfeasances, the findings of this study offer first and foremost implications for policy development and future research in the Cambodian context.

\section{CONCLUSIONS}

This study identified social and behavioural factors associated with depressive symptoms among Cambodian students at two universities. While causation could not be drawn between these factors and depression, we surmise that these factors were intertwined and thus need to be addressed in an integrated and holistic fashion.

These findings render three major implications. First, given the current educational reform and labour market that demand better quality and ergo more competition among university students, the correlates of depressive symptoms could not be more critical for tackling for the time being. Failure to ameliorate these factors would jeopardise the qualification and career development of this populace 
and finally the human capital for nation-building. Second, these findings warrant an acceleration of on-campus counselling services for university students throughout the course of studentship. Efforts should be invested in comprehensive screening and intervention programmes to diagnose those susceptible students early, offer immediate treatment and cater appropriate support. Universities could play very important roles in taking this research forward by providing future research outputs to improve mental health of the students that would in turn improve their academic outcomes. Ultimately, the jurisdiction of refining students' mental state should go beyond universities to families and pertinent governmental bodies at large, provided we are to assist the young to overcome their academic challenges and enjoy a prosperous postgraduation life. Further research could delve into changing lifestyles and their associations with depressive symptoms among a larger sample of university students. Furthermore, validation studies are required to develop and validate reliable instruments for use in Cambodian populations.

Acknowledgements The authors would like to thank the research assistants; representatives of students, faculty members and school administrators who supported the development of the study design and tools; and the study participants for their contribution to this study.

Contributors SY, KP and ST conceived research questions, designed the study and developed the research protocol and tools. SY and $\mathrm{CN}$ analysed the data and interpreted the results and drafted the manuscript. KP, PC and RY supported the protocol and tools development and were responsible for training and data collection. All authors contributed to the writing and approved the final manuscript.

Funding Data used for this analysis were collected as part of a larger study funded by the United States Agency for International Development (USAID).

Disclaimer Content of this paper is the responsibility of the authors and does not reflect the view of USAID or our respective institutions. The funder had no role in study design, data collection and analyses, decision to publish, or preparation of the manuscript.

Competing interests None declared.

Patient consent Obtained.

Ethics approval The National Ethics Committee for Health Research of the Ministry of Health, Cambodia approved this study (Reference no. 082NECHR), and a written informed consent was obtained from each participant.

Provenance and peer review Not commissioned; externally peer reviewed.

Data sharing statement Data used for this analysis are available upon request from the principal investigator (SY) at siyan@doctor.com. The data cannot be made publicly available due to ethical restriction.

Open access This is an open access article distributed in accordance with the Creative Commons Attribution Non Commercial (CC BY-NC 4.0) license, which permits others to distribute, remix, adapt, build upon this work non-commercially, and license their derivative works on different terms, provided the original work is properly cited, appropriate credit is given, any changes made indicated, and the use is non-commercial. See: http://creativecommons.org/licenses/by-nc/4.0/.

\section{REFERENCES}

1. Bayram N, Bilgel N. The prevalence and socio-demographic correlations of depression, anxiety and stress among a group of university students. Soc Psychiatry Psychiatr Epidemiol 2008;43:667-72.

2. Stewart-Brown S, Evans J, Patterson J, et al. The health of students in institutes of higher education: an important and neglected public health problem? J Public Health Med 2000;22:492-9.

3. Tomoda A, Mori K, Kimura M, et al. One-year prevalence and incidence of depression among first-year university students in Japan: a preliminary study. Psychiatry Clin Neurosci 2000;54:583-8.
4. Voelker R. Mounting student depression taxing campus mental health services. JAMA 2003;289:2055-6.

5. Wong JG, Cheung EP, Chan KK, et al. Web-based survey of depression, anxiety and stress in first-year tertiary education students in Hong Kong. Aust N Z J Psychiatry 2006;40:777-82.

6. Ibrahim AK, Kelly SJ, Adams CE, et al. A systematic review of studies of depression prevalence in university students. J Psychiatr Res 2013;47:391-400.

7. Lei XY, Xiao LM, Liu YN, et al. Prevalence of depression among Chinese university students: a meta-analysis. PLoS One 2016;11:e0153454.

8. Goebert D, Thompson D, Takeshita J, et al. Depressive symptoms in medical students and residents: a multischool study. Acad Med 2009;84:236-41.

9. Vázquez FL, Blanco V. Symptoms of depression and related factors among Spanish university students. Psychol Rep 2006;99:583-90.

10. Vázquez FL, Blanco V. Prevalence of DSM-IV major depression among Spanish university students. J Am Coll Health 2008;57:165-72.

11. Chen L, Wang L, Qiu XH, et al. Depression among Chinese university students: prevalence and socio-demographic correlates. PLOS One 2013;8:e58379.

12. Shamsuddin K, Fadzil F, Ismail WS, et al. Correlates of depression, anxiety and stress among Malaysian university students. Asian $J$ Psychiatr 2013;6:318-23.

13. Bayati A, Beigi M, Salehi M. Depression prevalence and related factors in Iranian students. Pak J Biol Sci 2009;12:1371-5.

14. Garlow SJ, Rosenberg J, Moore JD, et al. Depression, desperation, and suicidal ideation in college students: results from the American Foundation for Suicide Prevention College Screening Project at Emory University. Depress Anxiety 2008;25:482-8.

15. Khan MS, Mahmood S, Badshah A, et al. Prevalence of depression, anxiety and their associated factors among medical students in Karachi, Pakistan. J Pak Med Assoc 2006;56:583-6.

16. Steptoe A, Tsuda A, Tanaka Y, et al. Depressive symptoms, socio-economic background, sense of control, and cultural factors in university students from 23 countries. Int J Behav Med 2007;14:97-107.

17. National Collaborating Centre for Mental Health (UK). Depression: the treatment and management of depression in adults (updated edition). Leicester, UK: British Psychological Society, 2010.

18. Hysenbegasi A, Hass SL, Rowland CR. The impact of depression on the academic productivity of university students. J Ment Health Policy Econ 2005;8:145-51.

19. Heiligenstein E, Guenther G, Hsu K, et al. Depression and academic impairment in college students. J Am Coll Health 1996;45:59-64.

20. Meilman PW, Manley C, Gaylor MS, et al. Medical withdrawals from college for mental health reasons and their relation to academic performance. J Am Coll Health 1992;40:217-23.

21. Whitton SW, Whisman MA. Relationship satisfaction instability and depression. J Fam Psychol 2010;24:791-4.

22. Jeon HJ. Depression and suicide. J Korean Med 2011;54:370-5.

23. Furr SR, Westefeld JS, McConnell GN, et al. Suicide and depression among college students: a decade later. Prof Psychol 2001;32:97-100.

24. Harvey SB, Glozier N, Henderson M, et al. Depression and work performance: an ecological study using web-based screening. Occup Med 2011;61:209-11.

25. Mushquash AR, Stewart SH, Sherry SB, et al. Depressive symptoms are a vulnerability factor for heavy episodic drinking: a short-term, four-wave longitudinal study of undergraduate women. Addict Behav 2013;38:2180-6.

26. Buckner JD, Keough ME, Schmidt NB. Problematic alcohol and cannabis use among young adults: the roles of depression and discomfort and distress tolerance. Addict Behav 2007;32:1957-63.

27. Adams TB, Wharton CM, Quilter L, et al. The association between mental health and acute infectious illness among a national sample of 18- to 24 -year-old college students. J Am Coll Health 2008:56:657-64.

28. Bostanci M, Ozdel O, Oguzhanoglu NK, et al. Depressive symptomatology among university students in Denizli, Turkey: prevalence and sociodemographic correlates. Croat Med J 2005;46:96-100.

29. Eller T, Aluoja A, Vasar V, et al. Symptoms of anxiety and depression in Estonian medical students with sleep problems. Depress Anxiety 2006;23:250-6.

30. Newman DL, Moffitt TE, Caspi A, et al. Psychiatric disorder in a birth cohort of young adults: prevalence, comorbidity, clinical significance, and new case incidence from ages 11 to 21 . J Consult Clin Psychol 1996;64:552-62. 
31. Aalto-Setälä T, Marttunen M, Tuulio-Henriksson A, et al. One-month prevalence of depression and other DSM-IV disorders among young adults. Psychol Med 2001;31:791-801.

32. Kessler RC, Berglund P, Demler O, et al. Lifetime prevalence and age-of-onset distributions of DSM-IV disorders in the National Comorbidity Survey Replication. Arch Gen Psychiatry 2005;62:593-602.

33. Kessler RC, Walters EE. Epidemiology of DSM-III-R major depression and minor depression among adolescents and young adults in the National Comorbidity Survey. Depress Anxiety 1998;7:3-14.

34. Viñas Poch F, Villar E, Caparros B, et al. Feelings of hopelessness in a Spanish university population - descriptive analysis and its relationship to adapting to university, depressive symptomatology and suicidal ideation. Soc Psychiatry Psychiatr Epidemiol 2004;39:326-34.

35. Kaplan GA, Shema SJ, Leite CM. Socioeconomic determinants of psychological well-being: the role of income, income change, and income sources during the course of 29 years. Ann Epidemiol 2008;18:531-7.

36. Weissman MM, Bland RC, Canino GJ, et al. Cross-national epidemiology of major depression and bipolar disorder. JAMA 1996;276:293-9.

37. Marsella AJ. Thoughts on cross-cultural studies on the epidemiology of depression. Cult Med Psychiatry 1978;2:343-57.

38. Yi S, Poudel KC, Yasuoka J, et al. Sibling care, school performance, and depression among adolescent caretakers in Cambodia. Asian $J$ Psychiatr 2012;5:132-6.

39. Yi S, Poudel KC, Yasuoka J, et al. Exposure to violence in relation to depressive symptoms among male and female adolescent students in Cambodia. Soc Psychiatry Psychiatr Epidemiol 2013;48:397-405.

40. Nou L. Investigating stress symptomatology among Cambodian university students. Int Rev Mod Sociol 2013;39:133-64.

41. Kwok KW, Chan S, Heng C, et al. Scoping study: research capacities of Cambodia's universities. Phnom Penh: Development Research Forum in Cambodia, 2010.

42. Radloff LS. The CES-D scale: A self-report depression scale for research in the general population. Appl Psychol Meas 1977;1:385-401.

43. Shima S, Shikano T, Kitamura T, et al. New self-rated scale for depression (in Japanese). Japanese J Clin Psychiatry 1985;27:717-23.

44. Wada K, Tanaka K, Theriault G, et al. Validity of the center for epidemiologic studies depression scale as a screening instrument of major depressive disorder among Japanese workers. Am J Ind Med 2007;50:8-12.

45. National Institute of Statistics, Directorate General for Health, and ORC Macro. Cambodia demographic and health survey 2014. Phnom Penh: National Institute of Statistics and ORC Macro, 2014.

46. Ministry of Education, Youth, and Sport. Examining life experiences and HIV risks of young entertainment workers in four Cambodian cities. Phnom Penh: 46. Ministry of Education, Youth, and Sport, 2012.

47. Yi S, Poudel KC, Yasuoka J, et al. Role of risk and protective factors in risky sexual behavior among high school students in Cambodia. BMC Public Health 2010;10:477.

48. Yi S, Poudel KC, Yasuoka J, et al. Risk vs. protective factors for substance use among adolescents in Cambodia. J Subst Use 2011;16:14-26.

49. Steptoe A, Wardle J. The european health and behaviour survey the development of an international study in health psychology. Psychol Health 1996;11:49-73.

50. Center for Disease Control (CDC). Youth Risk Behavior Surveillance: National College Health Risk Behavior Survey-United States, 1995. MMWR CDC Surveill Summ 1997;46:1-54.

51. Center for Disease Control (CDC)/World Health Organization (WHO). The Global School-based Student Health Survey (GSHS). Atlanta, GA: CDC/WHO, 2012.

52. Bernstein DP, Stein JA, Newcomb MD, et al. Development and validation of a brief screening version of the childhood trauma questionnaire. Child Abuse Negl 2003;27:169-90.

53. Gandek B, Ware JE, Aaronson NK, et al. Cross-validation of item selection and scoring for the SF-12 Health Survey in nine countries: results from the IQOLA Project. International Quality of Life Assessment. J Clin Epidemiol 1998;51:1171-8.

54. Ware JE, Kosinski MA, Keller SD. SF-36 physical and mental health summary scales: a user manual. Boston: Health Institute, New England Medical Center, 1994.

55. Andrews B, Wilding JM. The relation of depression and anxiety to life-stress and achievement in students. Br J Psychol 2004;95:509-21.

56. Eisenberg D, Gollust SE, Golberstein E, et al. Prevalence and correlates of depression, anxiety, and suicidality among university students. Am J Orthopsychiatry 2007;77:534-42.

57. Lorant $\mathrm{V}$, Deliège $\mathrm{D}$, Eaton $\mathrm{W}$, et al. Socioeconomic inequalities in depression: a meta-analysis. Am J Epidemiol 2003;157:98-112.

58. World Bank. Improving macroeconomic and financial resilience: Cambodia economic. Washington DC: World Bank, 2016.

59. Teychenne M, Ball K, Salmon J. Physical activity and likelihood of depression in adults: a review. Prev Med 2008;46:397-411.

60. Azar D, Ball K, Salmon J, et al. The association between physical activity and depressive symptoms in young women: A review. Ment Health Phys Act 2008;1:82-8.

61. Schunert T, Khann S, Kao S, et al. Cambodian mental health survey 2012. Phnom Penh: Royal University of Phnom Penh, 2012.

62. McLaughlin D, Wickeri E. Special report: mental health and human rights in Cambodia. New York: Leitner Center for International Law and Justice, 2012.

63. Aberdein C, Zimmerman C. Access to mental health and psychosocial services in Cambodia by survivors of trafficking and exploitation: a qualitative study. Int J Ment Health Syst 2015;9:16. 